\section{PUDENDAL NERVE BLOCK}

BY

P. A. S. SAHAY, M.B., B.S., B.Sc.

Registrar in Obstetrics and Gynaecology, General Hospital, Halifax

With the passing of the high-forceps operation into obsolescence and reduction of the incidence of the socalled difficult mid-forceps operations, vaginal deliveries are now much safer. An important outcome has been the removal of the obvious objection to the employment of pudendal block as a routine and preferred form of analgesia for a great majority of vaginal deliveries, for which otherwise one would use general anaesthesia, with an occasional fatality. The objection on grounds of inadequacy is therefore no longer justified. General anaesthesia administered by a properly trained anaesthetist to a properly prepared patient is an ideal less commonly attained in obstetric emergencies. The obstetrician's usual preference for the lithotomy position for difficult manipulations, lack of delivery tables with emergency head-low tilting mechanism, and hence the risk of accidental aspiration of vomit, are discouraging problems without, as yet, an acceptable solution. The increasing popularity of pudendal block in this country and elsewhere is therefore a very welcome trend in modern obstetrics.

At the Halifax General Hospital, during a 14-months period ending January 31, 1958, it has been possible, by adopting a simple routine, combining parenteral pethidine hydrochloride and self-administered trichlorethylene ("trilene") with pudendal block, to reduce considerably the number of cases requiring general anaesthesia for operative vaginal deliveries. General anaesthesia was, however, used for all breech extractions and on occasion when preferred by the other members of the staff. Whereas previously the use of pudendal block was limited to occasions according to individual personal preferences, during the period under review an effort was made to employ this method when at all possible.

\section{Technique}

The patient is put in the lithotomy position. To block the pudendal nerve as it passes dorsal to the spine just before entering Alcock's canal, the middle and index fingers are placed in the vagina to palpate the ischial spine; a 6-in. $(15-\mathrm{cm}$.) pudendal needle fitted to an all-glass $20-\mathrm{ml}$. syringe containing $1 \%$ procaine hydrochloride solution, is guided through the perineum, entering at a point midway between the anus and the ischial tuberosity, to reach the inferior border of the spine. From here it is guided to its posterior surface and beyond, to reach the superior border and finally a point roughly $2 \mathrm{~cm}$. above it. Five $\mathrm{ml}$. of the procaine solution is injected at this point; the needle is then slightly withdrawn and a further $3 \mathrm{ml}$. is injected posterior to the spine, and finally $2 \mathrm{ml}$. at the inferior border of the spine. The needle is partially withdrawn and directed laterally to the ischial tuberosity, and $5 \mathrm{ml}$. is injected there to anaesthetize the perineal branches of the posterior femoral cutaneous nerve. To block the anterior labial branches of the ilio-inguinal nerve, the needle is again partially withdrawn and redirected anteriorly and superficially in the fold of the labium majus to a point slightly above the level of the clitoris, the remaining $5 \mathrm{ml}$. is then injected as the needle is gradually and finally completely withdrawn. The same procedure is repeated on the other side.

Always, before the actual injection, accidental entry into a blood vessel is ruled out, or a slight readjustment of the needle is made so that no blood enters the syringe on withdrawal of the plunger. With this method of approach, the needle is in close proximity to the pudendal nerve and the accompanying blood vessels are almost invariably pierced. This is quite a reassuring sign, and all that is then necessary is a slight medial readjustment of the needle. Pethidine hydrochloride, $50 \mathrm{mg}$., is now injected slowly into a vein, and another $50 \mathrm{mg}$. intramuscularly. Roughly three to five minutes is allowed for the development of perineal anaesthesia, which is as a rule verified by checking the cutaneous sensation before proceeding with the episiotomy or the delivery. When pains are felt the patients are allowed to self-administer trichlorethylene, its use thus being limited to obtaining analgesia during the uterine contractions. Training in the use of this technique is easy: even the junior house officers achieve success at a single attempt.

TABLE I.-Deliveries under Pudendal Block

\begin{tabular}{|c|c|c|c|c|c|c|c|c|c|}
\hline \multirow[b]{2}{*}{ 울 } & \multicolumn{4}{|c|}{ Forceps Deliveries } & \multicolumn{2}{|c|}{$\begin{array}{c}\text { Assisted } \\
\text { Breech } \\
\text { Deliveries }\end{array}$} & \multicolumn{2}{|c|}{ Episiotomies } & \multirow[b]{2}{*}{ Total } \\
\hline & $\begin{array}{c}\text { Scan- } \\
\text { zoni } \\
\text { Man- } \\
\text { cuvres }\end{array}$ & $\begin{array}{l}\text { Rota- } \\
\text { tions }\end{array}$ & Face & Others & $\begin{array}{l}\text { For- } \\
\text { ceps }\end{array}$ & Others & Face & Others & \\
\hline $\begin{array}{l}\mathbf{A} \\
\mathbf{B}\end{array}$ & $\begin{array}{l}3 \\
0\end{array}$ & $\begin{array}{r}17 \\
3\end{array}$ & $\begin{array}{l}1 \\
0\end{array}$ & $\begin{array}{l}27 \\
14\end{array}$ & $\begin{array}{l}1 \\
4\end{array}$ & $\begin{array}{r}14 \\
3\end{array}$ & $\begin{array}{l}2 \\
0\end{array}$ & $\begin{array}{r}12 \\
1\end{array}$ & $\begin{array}{l}77 \\
25\end{array}$ \\
\hline Total & 3 & 20 & 1 & 41 & 5 & 17 & 2 & 13 & 102 \\
\hline
\end{tabular}

\section{Results}

During the period under review 102 cases were delivered under pudendal block (Table I). Out of these, 77 were conducted either by me personally or by the house officer under my direct supervision, and in all these cases the above-described technique was followed strictly. An analysis of the cases is given in Table I under Group A. There were 48 forceps deliveries. Of these, 20 required either manual or forceps rotation; there was one face presentation; and the other 27 were vertex presentations in which the indications for forceps included the following: $(a)$ distress, either maternal or foetal; (b) inertia; (c) prophylactic for delay in the second stage or maternal indications such as heart disease. Assisted breech deliveries numbered 15, one of which required forceps to the after-coming head. In the remaining 14 , thought to be due to delay in the second stage, forceps application was indicated, but after liberal episiotomy and voluntary efforts of the patient spontaneous delivery occurred. In these cases, excluding of course those in which the foetal heart was known to be absent, the babies cried instantaneously after birth, on many occasions even before the cord could be clamped and cut. The other 25 cases have been placed separately in group B, because in those instances possibly the injection of pethidine was omitted and some minor deviations from the described technique could not be ruled out.

In the same period, after excluding breech extractions, either alone or preceded by internal version, 52 patients were delivered under general anaesthesia (Table In). 
These included 46 forceps and 6 assisted breech deliveries. Of the 154 probable cases, therefore, only 52 were actually subjected to general anaesthesia. Considering that no attempt was made to influence

TABLE II.-Deliveries under General Anaesthesia

\begin{tabular}{c|c|c|c|c|c|c}
\hline \multicolumn{2}{c|}{ Forceps Deliveries } & \multicolumn{2}{c|}{ Assisted Breech Deliveries } & Total \\
\hline Rotations & Others & Total & Forceps & Others & Total & \\
\hline 12 & 34 & 46 & 4 & 2 & 6 & 52 \\
\hline
\end{tabular}

individual preferences in favour of pudendal block, the reduction in the incidence of avoidable general anaesthesia by $66.2 \%$ in this period can be regarded as encouraging.

\section{Discussion}

Lately some interest has been focused on the technique of transvaginal pudendal nerve block (Kobak, Evans, and Johnson, 1956 ; Leshock, 1957). This would appear to be a simple and perhaps preferable approach, since the injection is given direct through the vaginal wall, at the posterior surface of the spine and above in the sacrosciatic notch-a procedure which ensures complete blocking of the pudendal nerve even if it divides higher up above the spine, as it often does. Unfortunately this does not take into account the anterior labial branches of the ilio-inguinal nerve and the perineal branches of the posterior femoral cutaneous nerve. Also it is not always possible to use the transvaginal technique owing to lack of space, and occasionally more than one attempt may be necessary to achieve a block (Kobak, Evans, and Johnson, 1956). As a routine procedure, therefore, it is desirable to adhere to the transperineal route and inject at all the three sites as described, through a single entry on each side. Use of a point midway between the ischial tuberosity and the anus as the site of entry has the advantage of bringing the posterior surface of the ischial spine and the point $2 \mathrm{~cm}$. above its superior border within direct and easy reach of the 6-in. $(15-\mathrm{cm}$.) pudendal needle. This point also happens to be very conveniently placed in relation to the remaining two sites of injection.

This technique does not include local infiltration of the perineal skin, and thus there is no artificial oedema of the tissues to make any repair work difficult. The conspicuous absence of vulval and vaginal haematomas from the present series of cases makes one wonder whether or not, in the few instances where they are said to appear following transperineal pudendal block, the cause lies entirely in the traumatic nature of the deliveries, forceps or otherwise.

Even a single dose of $100 \mathrm{mg}$. of pethidine may raise the pain threshold by $50 \%$ (Bourne and Williams, 1948a). To use this drug with advantage to enhance the effectiveness of pudendal block analgesic one would require to use it reasonably close to the time of the delivery, a procedure which is generally in disfavour. It has been shown that up to 30 minutes after birth the oxygen saturation in the arterial blood of infants, born of mothers receiving $100 \mathrm{mg}$. of pethidine hydrochloride and $0.4 \mathrm{mg}$. of scopolamine within two to four hours of delivery, remains significantly low when compared with those in the control group (Taylor et al., 1955). This measurable depression in the blood oxygen level was, however, not thought to be injurious. The use of pethidine in doses varying from $100 \mathrm{mg}$. to $400 \mathrm{mg}$. or more during labour is very common. To counteract the possible depressant effect on the respiration of the baby, intravenous injection of $10 \mathrm{mg}$. of nalorphine hydrobromide given to the mother about five minutes before the delivery has been recommended (Bourne and Williams, 1958). Unfortunately it also neutralizes the analgesic action of pethidine (Micks, 1957). In the routine described in the present paper, a slow injection of $50 \mathrm{mg}$. of pethidine hydrochloride is given intravenously while still waiting for the perineal analgesia to develop. The desired effect is achieved immediately. The birth of the baby usually takes place within five to seven minutes after the injection. The babies in the cases reported under group A (Table I) did not show any clinical evidence of respiratory depression; on the contrary, many of them, even in the presence of foetal distress, cried spontaneously. The intramuscular injection of $50 \mathrm{mg}$. of pethidine, given at the same time, assures the prolongation of the drug's beneficial action throughout the time required for repair of the episiotomy; it also provides rest and sedation in the immediate post-partum period. In the 77 cases (Table I, group A), no ill-effects of intravenous administration of pethidine were noted. The fear of sudden fall in blood pressure after intravenous pethidine (Holland and Bourne, 1955) is not substantiated.

Self-administered trichlorethylene, when used for analgesia in labour, does not affect the oxygen saturation of the baby's arterial blood (Taylor et al., 1955). The patients are therefore allowed the benefit of its use by the usual method.

The proper choice of analgesic agent for pudendal block is equally important. A total of $40 \mathrm{ml}$. of $1 \%$ lignocaine hydrochloride is not only quite safe but also very effective and speedy, and has wonderful spreading properties. Gross overdosage of lignocaine, however, is not easily tolerated, and death following such overdosage has been reported (Lock and Greiss, 1955). It is nearly twice as toxic as procaine. For beginners, therefore, the importance of caution in the matter of dosage cannot be stressed enough. In this series, $40 \mathrm{ml}$. of $1 \%$ procaine hydrochloride was employed for the block. Using plain procaine, one is at the slight disadvantage of having to wait three to five minutes for the analgesia to develop. This is usually remedied by adding hyaluronidase, which increases its spreading properties. Procaine when used with hyaluronidase alone produces a very short-lasting analgesia (Kobak, Evans, and Johnson, 1956), but the addition of $1: 1,000$ adrenaline $(0.5 \mathrm{ml}$. adrenaline to $30 \mathrm{ml}$. of procaine) produces a comparatively long-lasting analgesia (Kobak, Evans, and Johnson, 1956). Addition of even minute quantities of adrenaline as above may produce a marked adrenaline effect characterized by complete cessation or otherwise weakening of uterine contraction and tone, lasting for as long as 20 minutes (Woolsey, 1955). The resulting period of uterine inertia following the use of adrenaline in the procaine-hyaluronidase mixture requires recognition if haemorrhage caused by detachment of the placenta before the return of the uterine tone is to be avoided. A wait of 20 minutes for the return of the uterine tone before attempting to deliver may cost the life of the baby, which in a sudden case of foetal distress is the very thing one is trying to prevent.

Use of trichlorethylene, self-administered during labour, is an established and safe practice, but the drug sometimes causes cardiac arrhythmias, and when in combination with adrenaline may give rise to ventricular 
fibrillation (Bourne and Williams, 1948b; Lock and Greiss, 1955). This may hold true also if, after an initial pudendal block with procaine-hyalase-adrenaline mixture, it becomes necessary to administer general anaesthesia in an emergency. Plain procaine was therefore considered to be a safer agent to use in the cases above. An effective pudendal block, achieved in this way, assures one of the co-operation of the mother, who in most instances is thrilled to have actively participated in the birth of her child and is glad to be able to see and hear her baby cry for the very first time.

\section{Summary and Conclusions}

A technique for pudendal nerve block anaesthesia for routine use is described.

Cases delivered under pudendal block and those under general anaesthesia are recorded and analysed.

An unconventional use of pethidine hydrochloride and self-administered trichlorethylene as an adjunct to pudendal block is described and discussed.

A critical study of local analgesic agents commonly used for this purpose has been made.

It is concluded that $40 \mathrm{ml}$. of $1 \%$ procaine hydrochloride (plain), injected according to the technique described above, produces a satisfactory pudendal nerve block and perineal analgesia; also that the perineal analgesia so developed, when combined with the use of pethidine and self-administered trilene analgesia, permits most of the operative vaginal deliveries to be carried out without general anaesthesia.

ADDENDUM.-Since the preparations for this paper were completed, $40 \mathrm{ml}$. of $1 \%$ lignocaine hydrochloride has been substituted in place of procaine. It is perhaps a very premature observation at this stage, but it appears that so far it has lived up to its reputation, and lignocaine, when used with proper caution, may prove to be better than procaine. It is more potent and produces a more prompt and extensive analgesia. It is as safe as procaine if the strength of $1 \%$ is not exceeded. While $2 \%$ procaine may in some instances be used for nerve blocks, lignocaine in this strength should on no account be used for pudendal block.

I am grateful to Mr. J. N. I. Emblin for his constant guidance, both in the clinical work and in the preparation of this paper, and also for his permission to publish. I am also thankful to Drs. S. K. Ghai, P. K. Irani, and H. Watson for their co-operation and participation; to Miss S. M. Green for making available the obstetric records; and to Sister L. Townend and her staff for their muchappreciated help in the labour wards.

\section{REFERENCES}

Bourne, A. W., and Williams, L. H. (1948a). Recent Advances in Obstetrics and Gynaecology, 7 th ed., p. 89. Churchill, London.

— (1948b). Ibid., 7th ed., p. 106 (1958). Ibid., 9th ed., p. 187.

Holland, Sir E., and Bourne, A. (1955). British Obstetrics and Gynaecological Practice: Obstetrics, p. 1045. Heinemann, London.

Kobak, A. J., Evans, E. F., and Johnson, G. R. (1956). Amer. J. Obstet. Gynec., 71,981 .

Leshock, J. C. (1957). Ibid., 74, 1128.

Lock, F. R., and Greiss, F. C., jun. (1955). Ibid., 70, 861.

Micks, R. H. (1957). The Essentials of Materia Medica, Pharmacology and Therapeutics, 7th ed., p. 31. Churchill, London.

Taylor, E. S., Fumetti, H. H. von, Essig, L. L., Goodman, S. N., and Walker, L. C. (1955). Amer. J. Obstet. Gynec., 69, 348 .

Woolsey, E. L. (1955). Ibid., 69, 131.

\section{MANIFESTATIONS AND AETIOLOGY OF HYPERTENSION IN THE COLOURED AND BANTU}

\author{
BY
}

\author{
B. N. FRASER, M.B., M.R.C.P.Ed. \\ Coronation Hospital, Johannesburg
}

Hypertension is known to be common in the Bantu in South Africa. A survey was made among both urban and country Bantu by Ordman (1948), who found a significant proportion with a systolic blood pressure of over $150 \mathrm{~mm}$. $\mathrm{Hg}$ and a diastolic over 90 in all age groups, though there was a sharp drop in incidence of high blood pressure in males over the age of 60 .

Comstock (1957) carried out a survey among both Whites and Negroes in the Southern United States, and his figures showed that the average blood-pressure readings, both systolic and diastolic, are higher in the American adult Negro than his white counterpart. Lennard and Glock (1957), in an appraisal of the distribution of hypertension among Negroes and Whites in the United States, stated that all studies support the conclusion that Negroes more often have essential hypertension, hypertensive heart disease, hypertensive cardiovascular disease or related disorders, than Whites.

Reports from other parts of Africa other than South Africa have revealed variable results. Gelfand (1957) stated that in Rhodesia hypertension, both essential and secondary to chronic nephritis, is common, but he was unable to decide whether it was as frequent as, less frequent, or more frequent than in the white population. He felt comparison between the two races was difficult, since the Europeans' expectation of life is on the whole much higher.

Donnison's (1929) investigation of the blood pressure of males among tribes in the highlands of Kenya showed that up to the fourth decade the average blood pressure was similar to that of European males, but that thereafter there was a tendency to lower pressures. Williams (1944) stated that the majority of cases seen by him in Uganda were secondary to nephritis and urethral stricture. He considered essential hypertension to be rare.

It was decided to investigate hypertension among Bantu and Coloured in-patients as regards incidence, aetiology, morbidity, and mortality. Cases admitted to one of the two medical units at Coronation Hospital during the period January 1, 1955, to December 31, 1956, were used for this purpose. However, owing to the infrequency with which permission was obtained for post-mortem examination, a longer period was taken for investigating necropsy material as regards the incidence of underlying renal disease. The figures of $140 \mathrm{~mm}$. $\mathrm{Hg}$ systolic and $90 \mathrm{~mm}$. $\mathrm{Hg}$ diastolic were taken as the dividing line between raised and normal blood pressure. This was perhaps not as desirable as relating the blood-pressure reading of each case to a figure taken from a table showing the average blood pressure for that age and sex group, as has been suggested by Pickering (1955). However, no such tables have been compiled for the South African Bantu and Coloured. Comstock's (1957) survey in America has shown that in all age groups the average blood pressure is higher in the American Negro, and the same might well apply to the South African Bantu. Also in many of the Bantu 